\title{
Soil Moisture and Crop Evapotranspiration Forecast for Winter Wheat Based on Weather Information in North China Plain
}

\author{
Zhandong Liu, Anzhen Qin*, Aiwang Duan, Jiyang Zhang, Jingsheng Sun, Dongfeng Ning, Ben Zhao, Zhaorong Mi \\ and Zugui Liu \\ Key Laboratory of Crop Water Use and Regulation, Ministry of Agriculture, Farmland Irrigation Research Institute, Chinese \\ Academy of Agricultural Sciences, Xinxiang 453002, China. \\ ${ }^{*}$ Corresponding author
}

\begin{abstract}
Soil moisture and crop evapotranspiration (ETc) forecast based on weather information is a basis for realizing precise irrigation, which could be an innovative technique for water-saving strategy in irrigated district. Combined with longterm experimental data in People's Victory Canal irrigated district, we put forward a systematic soil moisture forecast method for winter wheat using related weather information. In this study, hourly soil moisture was automatically monitored by a soil moisture monitoring system. Weather information for the following two weeks was automatically acquired. Combined with $E_{c}$, soil moisture forecast can be used to predict irrigation time and amount which differs among growth stages of winter wheat. In particular, irrigation time can be decided by monitoring soil moisture when reaching to lower limit of soil moisture for winter wheat, and the irrigation amount can be determined by calculating soil water storage needed to meet planned wetting layer according to crop growth monitoring. Parameters in soil moisture and crop evapotranspiration forecast models were determined using Levenberg-Marquardt regression. Validation test suggests that the models we developed are reliable. We conclude that the models can serve as a useful tool for future irrigation forecast.
\end{abstract}

Keywords-irrigation forecast; prediction model; crop water requirement; precipitation

\section{INTRODUCTION}

Soil moisture forecast is a dynamic process based on weather forecast information updated hourly by China Meteorological Administration [1]. Through estimating crop evapotranspiration $\left(\mathrm{ET}_{\mathrm{c}}\right)$ by prediction model, and measuring current soil moisture by soil moisture monitoring system, when and how much water should be irrigated for crops can be predicted [2]. In particular, future soil moisture simulation is mainly dependent upon weather forecast information and current soil moisture monitoring. To precisely forecast irrigation, best-fitted prediction model is needed to estimate $\mathrm{ET}_{\mathrm{c}}$. Nowadays, it has been widely used for $\mathrm{ET}_{\mathrm{c}}$ prediction models established on water balance equation [3]. The core technique for when and how much water need to be irrigated is based on accurate soil moisture monitoring and precise weather forecast [4]. Therefore, the accuracy of irrigation prediction largely depends on how to acquire precise weather data for the following days. It is equally important that we should accurately estimate $\mathrm{ET}_{\mathrm{c}}$ by coupling reference evapotranspiraion $\left(\mathrm{ET}_{0}\right)$ with crop coefficient $\left(\mathrm{K}_{\mathrm{c}}\right)$ for irrigation forecast [5]. The estimate of $\mathrm{ET}_{0}$ is usually based on measurable and accessible climatic factors such as air temperature, solar radiation, and precipitation etc. [6]. Given that air temperature in weather forecast is a quantified figure that can be directly used and accumulated, model for accumulated air temperature simulation can be used to calculate $\mathrm{ET}_{\mathrm{C}}$. As a result, choosing an optimal model for $\mathrm{ET}_{\mathrm{c}}$ and soil moisture forecast can be applied to improve the accuracy of irrigation forecast when parameters needed are of high accuracy [7]. The feasibility of a model usually needs to be validated through field experiments. In this study, we hypothesized that soil moisture forecast model developed based on weather forecast information was suitable and reliable for forecasting the irrigation time and amount in the People's Victory Canal irrigated district, North China Plain.

\section{WATER BALANCE EQUATION}

Soil moisture forecast is basically established on soil moisture monitoring system and crop evapotranspiration $\left(\mathrm{ET}_{\mathrm{c}}\right)$ estimated by weather forecast information [8]. That is, a forecast of an increase or decline of soil water content in the root zone, which changes with crop growth stages, can be estimated by subtracting predicted $\mathrm{ET}_{\mathrm{c}}$ from the current $\mathrm{ET}_{\mathrm{c}}$, then we got the how much water should be consumed for the following days. Thus, it provides a possibility for forecasting irrigation time and amount for a given date. Water balance equation, which is used to calculate current $\mathrm{ET}_{\mathrm{c}}$, is established to a depth equal to planned wetting layer [3]:

$$
W_{i}=W_{0}+W_{r i}+P_{e i}+I_{i}-E T_{c i}-G_{i}-R_{i}
$$

where $W_{0}$ and $W_{i}$ are soil water storage $(\mathrm{mm})$ in planned wetting layer at the initial $(0)$ and current time $(i) ; W_{r i}$ is increased soil water storage $(\mathrm{mm})$ due to increasing planned wetting layer with crop growth proceeding; $I_{i}$ is irrigation amount (mm); $P_{e i}$ is effective precipitation (mm); $E T_{c i}$ is future crop evapotranspiration (mm) to be predicted by an empirical model; $R_{i}$ is surface runoff (mm); $G_{i}$ is ground water recharge (mm). 
The runoff is negligible due to less precipitation in the People's Victory Canal irrigated district during the entire growth period of winter wheat [9]. Thus $R_{i}$ is assumed to be 0 . In the mean time, the ground table is below $5 \mathrm{~m}$, therefore the upward movement is also neglected, i.e., $G_{i}$ is assumed to be 0 . Thus, the equation can be simplified as:

$$
W_{i}=W_{0}+W_{r i}+P_{e i}+I_{i}-E T_{c i}
$$

Initial soil water content $\left(W_{0}\right)$, current soil water content in planned wetting layer $\left(W_{t}\right)$, and increased soil water storage due to the planned wetting layer deepening with crop growth $\left(W_{r}\right)$ can be obtained by field observation. Soil water storage $(\mathrm{mm})$ in the planned wetting layer is a product of volumetric water content $\left(\mathrm{cm}^{3} \cdot \mathrm{cm}^{-3}\right)$ and soil depth $(\mathrm{cm})$ [9]. Irrigation amount $\left(I_{i}\right)$ is measured using a flow meter at the recharge end of a water pipe system.

\section{PREDICTION MODELS}

$\mathrm{ET}_{\mathrm{c}}$ can be calculated from meteorological data and crop coefficients $\left(\mathrm{K}_{\mathrm{c}}\right) . \mathrm{ET}_{\mathrm{c}}$ is considered as a combined effect of the climate factors and crop growth on crop water requirements, which is illustrated by $\mathrm{ET}_{0}$ and $\mathrm{K}_{\mathrm{c}}$.

\section{A. Prediction Model for Crop Evapotranspiration}

Calculation of $\mathrm{ET}_{\mathrm{ci}}$ can be achieved by multiplying reference evapotranspiration $\left(E T_{0 i}\right)$ with crop coefficient $\left(K_{c i}\right)$ at a certain growth stage [3], and it can be expressed as:

$$
E T_{c i}=K_{c i} \cdot E T_{0 i}
$$

If soil water is deficit, the calculation should introduce a correction factor $\left(K_{s i}\right)$ :

$$
E T_{c i}=K_{s i} \cdot K_{c i} \cdot E T_{0 i}
$$

When $K_{s i}$ equals 1.0 , the simulation of $E T_{c i}$ is considered under non-water stress condition [2].

\section{B. Prediction Model for Reference Evapotranspiration}

Estimate of $\mathrm{ET}_{0}$ is a basis for soil moisture and $E T_{c}$ forecast. Because Harg model explicitly accounts for solar radiation and temperature [11], $\mathrm{ET}_{0}$ simulated by Harg model can be expressed as:

$$
E T_{0}=0.0023 \cdot \frac{1}{\lambda} \cdot\left(T_{\max }-T_{\min }\right)^{0.5}\left(\frac{T_{\max }+T_{\min }}{2}+17.8\right) R_{a}
$$

where $R a$ is solar radiation $\left(\mathrm{MJ} \cdot \mathrm{m}^{-2} \cdot \mathrm{d}^{-1}\right) ; \lambda$ is latent heat of vaporization with a value of $2.45 \mathrm{MJ} \cdot \mathrm{kg}^{-1}$ [12]; $T_{\max }$ and $T_{\min }$ are maximum and minimum air temperature $\left({ }^{\circ} \mathrm{C}\right)$, respectively.

Comparing the results of $\mathrm{ET}_{0}$ calculated by Harg model to that by Penman-Monteith (PM) model using a long term
(1951-2002) ten-day meteorological data from Xinxiang city, North China Plain, the two calculation methods showed good consistency in $\mathrm{ET}_{0}$ simulation, with a mean deviation of $3.5 \mathrm{~mm}$, and mean relatively deviation of $10 \%$ (Figure 1). Our results are consistent with the findings of Liu and Luo (2010) [13], who conducted a similar evaluation in North China Plain. The correlation coefficient $\left(\mathrm{r}^{2}\right)$ between the two $\mathrm{ET}_{0}$ results reached 0.81, showing a significant correlation between Harg and PM methods $(P<0.05)$.
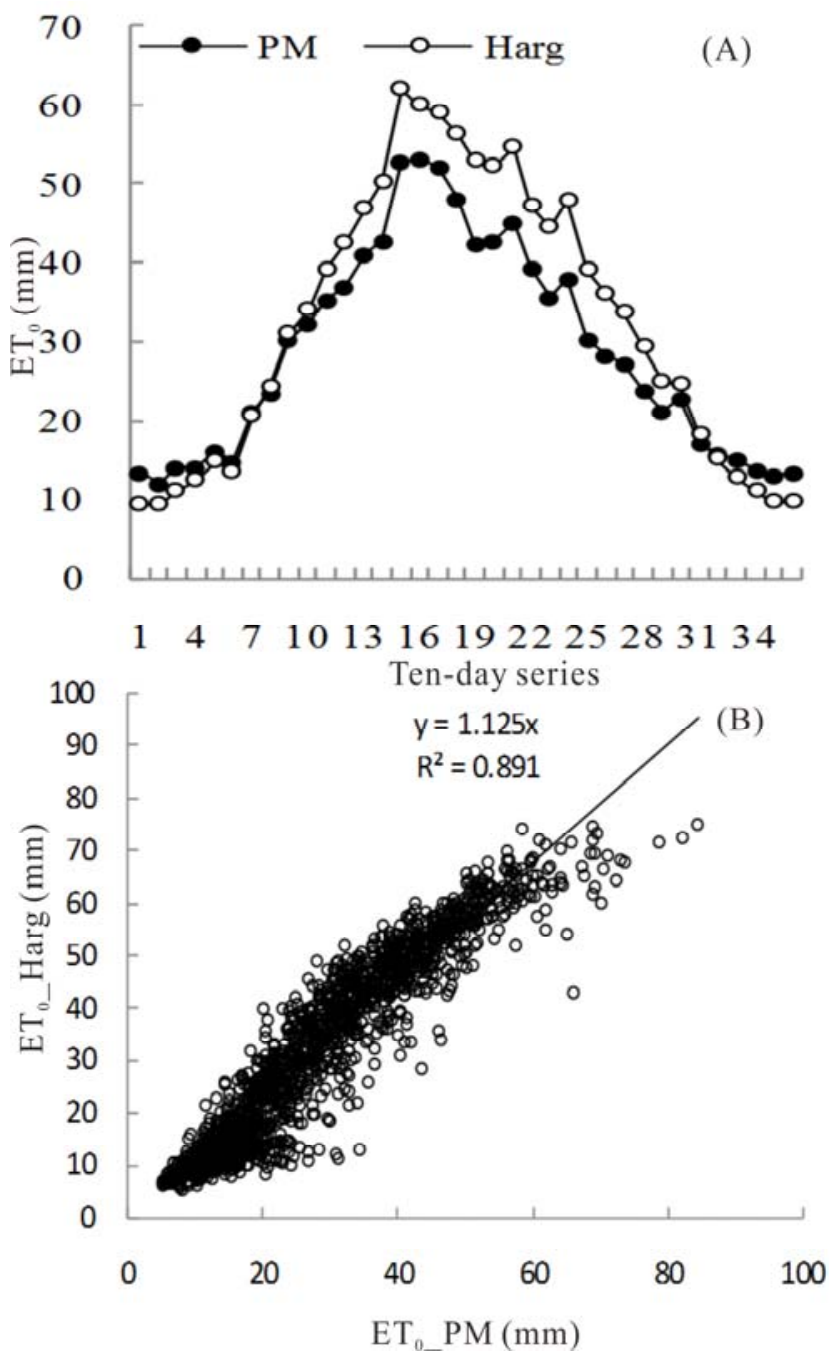

FIGURE I. (A) ET0 CALCULATED USING HARG MODEL AT TENDAY SERIES , AND (B) THE CORRELATION ANALYSIS BETWEEN ETO CALCULATED BY HARG AND BY PM MODELS.

In order to improve the accuracy of the predicted $\mathrm{ET}_{0}$ values, some corrections for parameters like $K, n$, and $T_{\text {off }}$ need to be iterated in Harg model using Levenberg-Marquardt regression:

$$
E T_{0}(H G)=K \frac{1}{\lambda}\left(T_{\max }-T_{\min }\right)^{n}\left(\frac{T_{\max }+T_{\min }}{2}+T_{\text {off }}\right) R_{a}
$$

where $K$ is a constant to be fitted for determining the slope; $n$ is an empirical exponential coefficient to be fitted. $T_{\text {off }}$ is an 
empirical temperature value calibrated to offset biases in " $T_{\max }-T_{\min }$ " at different latitudes. To calibrate the Harg model, parameters were iterated into Levenberg-Marquardt Algorithm using Statistical Analysis Software (SPSS 19.0, SPSS Institute Inc., USA). After the iteration, the best fitted values for the parameters are $0.008(K), 0.796(n)$, and $29.506\left(T_{\text {off }}\right)\left(\mathrm{r}^{2}=0.907\right.$, $P<0.01)$, respectively. The parameters estimated in this study are similar to the results of Tang et al. (2016) [12], who concluded some key parameters for the model using Harg formula in the Huang-Huai-Hai Plain.

\section{Determination of Crop Coefficient (Kci)}

For a given cultivar of winter wheat, $K_{c i}$ is mainly controlled by crop growth stages, and is also linked with crop canopy development [3]. Our study showed that there existed a significant linear relationship between leaf area index ( $L A I)$ and $K_{c i}$ :

$$
K_{c i}=a \cdot L A I+b
$$

where $a$ and $b$ are the slope and interception for the equation. By iterating field observed data into Levenberg-Marquardt regression, it was suggested that $0.14(a)$, and $0.3918(b)$ be the best fittest parameters $\left(\mathrm{r}^{2}=0.928, P<0.01\right)$.

Except the indigenous genetic traits, cumulative relative growth degree days $\left(\mathrm{RGDD},{ }^{\circ} \mathrm{C} \cdot \mathrm{d}\right)$ during the growing season is a major factor determining crop growth and development [14]. Since RGDD is a product of accumulated air temperature $\left({ }^{\circ} \mathrm{C}\right.$ ) and elapsed time (d) for fulfilling a life cycle of crops, the requirement of crops to RGDD is always stable and unchangeable. Namely, RGDD must be adequate to meet the crop demand. Our study showed that there existed a good correlation between RGDD and LAI, and the regression between RGDD and LAI was fitted to $j-t h$ order $(j=0, \ldots \ldots, 5)$ Logistic curve, where the fifth-order Logistic curve had the best goodness of fit (Figure 2):

$$
L A I=\frac{b \cdot L A I_{\max }}{1+\exp \left(\sum_{j=0}^{5} a_{j} R G D D^{j}\right)}
$$

where $L A I_{\max }$ is the largest $L A I$ value during the entire growth stage; $R G D D$ is the relative cumulative growth degree days (that is, the ratio of phase cumulative $R G D D$ to the whole $R G D D) ; j$ is the $j$-th power of the Logistic curve; $a_{j}$ $(j=0, \ldots \ldots, 5)$ and $b$ are empirical coefficients to be fitted. After regression by fifth-order, it was suggested that $24.84\left(a_{0}\right)$, $161.4\left(a_{1}\right), 374\left(a_{2}\right),-392.6\left(a_{3}\right), 169.2\left(a_{4}\right),-11.46\left(a_{5}\right)$, and $1.169(b)$ be the best fitted parameters $\left(\mathrm{r}^{2}=0.977, P<0.01\right)$. Our results are in good agreement with the findings of Wang et al., (2011) [15], who conducted a similar simulation between $L A I$ and $R G D D$, but we obtained a higher fitness for the model due to a higher order curve than that of Wang et al. (2011) [15].

When integrate the two models into one, a model for predicting crop coefficient $\left(K_{c i}\right)$ based on RGDD can be established. It is necessary that, when to predict $K_{c i}$ using the integrated model, we should consider the freezing period when a very low temperature might occur in the wintering period of winter wheat, and correct the $K_{c i}$ to be 0.4 rather than a value predicted by the model [13]. While before and after the wintering period, the predicted $K_{c i}$ values can be acceptable for calculating $E T_{c}$.

\section{Determination of Calibration Coefficient for Soil Moisture (Ksi)}

If observed soil water content is significantly lower than the critical value that triggers crop wilting, $\mathrm{ET}_{\mathrm{c}}$ will be markedly constrained [3]. Otherwise, soil water content will normally not be a constraint to depressing $\mathrm{ET}_{\mathrm{c}}$. Thus, the $K_{s i}$ can be expressed as:
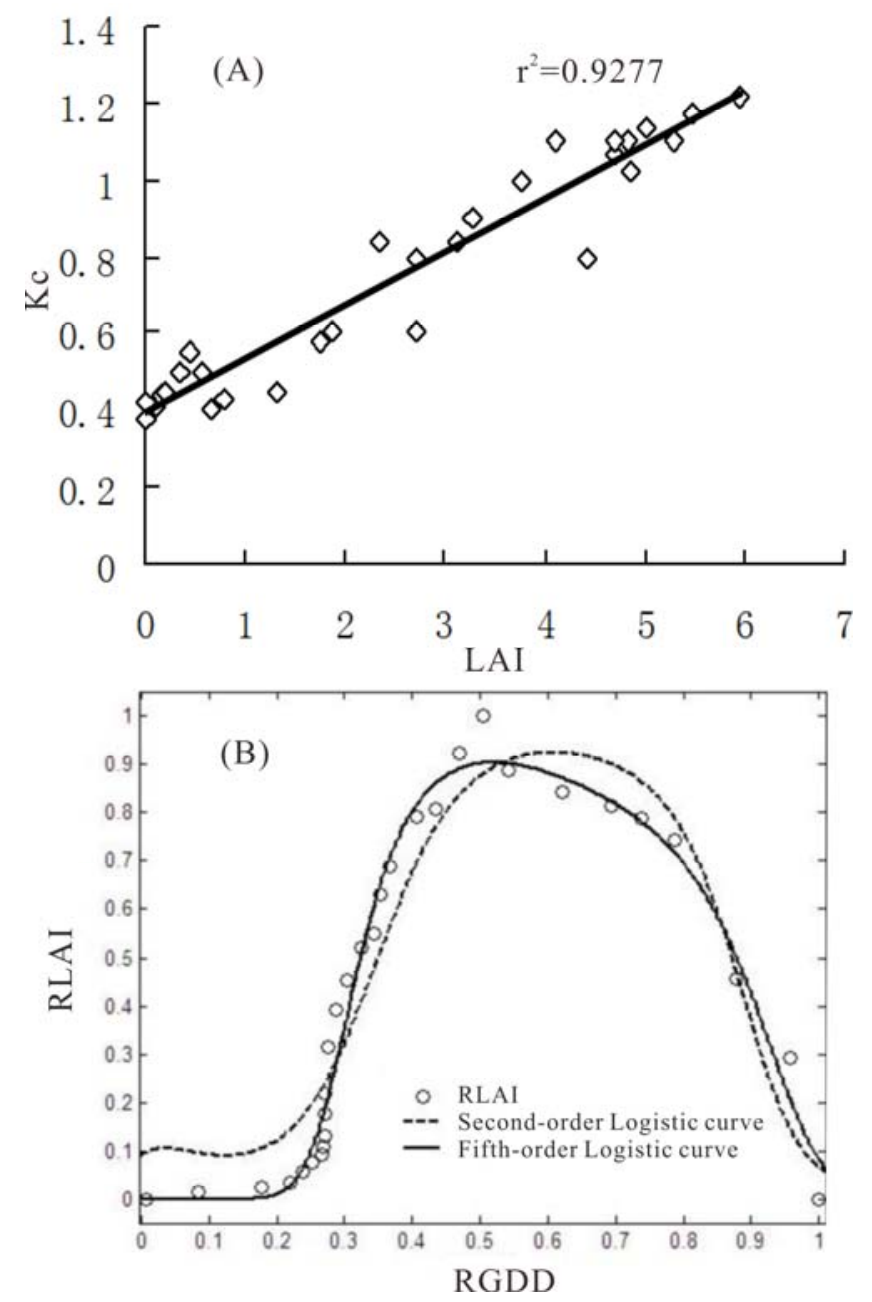

FIGURE II. (A) RELATIONSHIP BETWEEN CROP COEFFICIENT (KC) AND LEAF AREA INDEX (LAI), AND (B) RELATIONSHIP BETWEEN CUMULATIVE RELATIVE GROWTH DEGREE DAYS $\left(\mathrm{RGDD},{ }^{\circ} \mathrm{C} \cdot \mathrm{D}\right)$ AND RELATIVE LEAF AREA INDEX (RLAI).

$$
K_{s i}=\left(\frac{\theta_{i}-\theta_{u p}}{\theta_{j}-\theta_{u p}}\right)^{d} \quad\left(\theta_{i}<\theta_{j}\right)
$$


where $d$ is an empirical coefficient obtained from field observation, and it changes with crop growth stages and soil water status. $\theta_{i}$ is mean soil water content during a given growth phase; $\theta_{u p}$ is the wilting point; $\theta_{j}$ is the critical soil water content. According to the ranges of $K_{c i}$ changing with crop growth stages, four growth stages were classified as follow: sowing to wintering stage, wintering to turning-green stage, turning-green to tasseling stage, and tasseling to maturity. After iteration using Levenberg-Marquardt Algorithm, it was suggested that the corresponding $\theta_{j}$ values be 23.07, 22.52, 20.20, and 22.68 for the four growth phases of winter wheat, and the corresponding $d$ values be 0.8156 , $0.9563,0.7584$, and 0.8753 , respectively. Our results are consistent with the findings of Wang et al. (2010) [16], who established a simulation model based on plant height and leaf area index for winter wheat in the North China Plain. According to Wen et al. (2015) [17], those models can be integrated into one model for predicting $\mathrm{ET}_{\mathrm{c}}$ so that they can help local farmers and district governors determine irrigation time and amount.

\section{E. Validation of the Model for Forecasting Soil Moisture}

The ten-day soil water content can be predicted by the established $\mathrm{ET}_{\mathrm{C}}$ model (Figure 3). Also, the predicted soil moisture values can be updated hourly according to the weather forecast information and observed soil water content. Compared the predicted and observed soil water content during the winter wheat growing season in 2012 and 2013, they basically showed good consistency, with a mean deviation of $2.45 \%$. This indicated that the established soil moisture forecast model is reliable, and can serve as a useful tool for irrigation forecast in People's Victory Canal irrigated district, Xinxiang city, North China Plain.

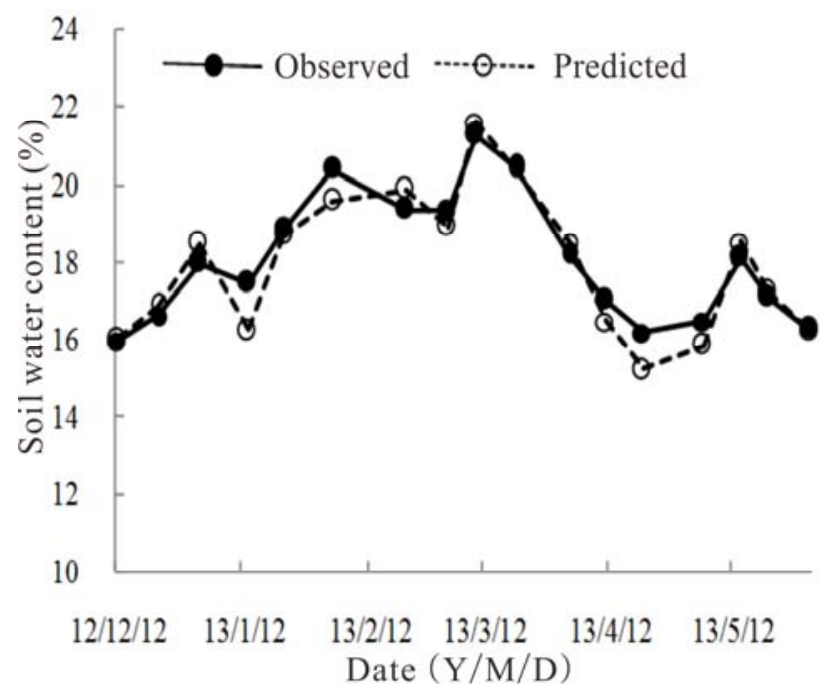

FIGURE III. PREDICTED SOIL WATER CONTENT IN COMPARISON TO OBSERVED SOIL WATER CONTENT USING THE SOIL MOISTURE FORECAST MODEL.

\section{CONCLUSIONS}

The model for predicting daily $\mathrm{ET}_{\mathrm{c}}$ based on weather forecast information has proven to be reasonable and reliable in the present study. On the basis of the model, a prediction model for simulating soil moisture has been established, and can be adopted to forecast daily soil moisture dynamics in the following two weeks in winter wheat growing season. Our study showed that there existed a very good agreement between the observed and predicted values of soil moisture, as well as $\mathrm{ET}_{\mathrm{c}}$, indicating a good model performance. Taking lower limit of soil moisture and planned wetting layer into account, the models can serve as a strong support for establishing a irrigation forecast model for People's Victory Canal irrigated district, North China Plain, in the near future.

\section{ACKNOWLEDGMENT}

The study was supported by the National Natural Science Foundation (51309226), the Central Public-interest Scientific Institution Basal Research Fund (Farmland Irrigation Research Institute, CAAS, 1610262016004, and 1610262016006), and the Agricultural Science and Technology Innovation Program (ASTIP).

\section{REFERENCES}

[1] R. Ren, Y. Yang, M. Cai, and J. Rao, "Understanding the systematic air temperature biases in a coupled climate system model through a processbased decomposition method,” Clim. Dyn., vol. 45, pp. 1801-1817, 2015.

[2] R. Allen, A. Clemmens, C. Burt, K. Solomon, and T. Halloran, "Prediction accuracy for project-wide evapotranspiration using crop coefficient and reference evapotranspiration,” J. Irrig. Drain Eng. ASCE, vol. 131, pp. 24-36, 2005.

[3] Z. Liu, A. Qin, B. Zhao, S. Ataulkarim, J. Xiao, and J. Sun, et al., "Yield response of spring maize to inter-row subsoiling and soil water deficit in northern China,” Plos One, vol. 11:e0153809, 2016.

[4] Q. Zhu, K. Liao, Y. Xu, G. Yang, S. Wu, and S. Zhou, "Monitoring and prediction of soil moisture spatial-temporal variations from a hydropedological perspective: A review,” Soil Res., vol. 50, pp. 625-637, 2013.

[5] L. Odhiambo, and S. Irmak, "Evaluation of the impact of surface residue cover on single and dual crop coefficient for estimating soybean actual evapotranspiration,” Agric. Water Manage., vol. 104, pp. 221-234, 2012.

[6] L. Nandagiri, and G. Kovoor, "Performance evaluation of reference evapotranspiration equations across a range of Indian climates,” J. Irrig. Drain. Eng., vol. 132, pp. 238-249, 2006.

[7] R. Allen, L. Pereira, M. Smith, D. Raes, and J. Wright, "FAO-56 dual crop coefficient method for estimating evaporation from soil and application extensions,” J. Irrig. Drain Eng. ASCE, vol. 131, pp. 2-13, 2005.

[8] K. Soulis, S. Elmaloglou, and N. Dercas, "Investigating the effects of soil moisture sensors positioning and accuracy on soil moisture based drip irrigation scheduling systems,” Agric. Water Manage., vol. 148, pp. 258268, 2015.

[9] Z. Liu, A. Qin, D. Ning, B. Zhao, Z. Zhang, and Z. Liu, et al., "Subsoiling effects on grain yield and water use efficiency of spring maize in northern China,” Int. Agric. Engin. J., vol. 25, pp. 9-19, 2016.

[10] A. Biswas, "Landscape characteristics influence the spatial pattern of soil water storage: similarity over times and at depths,” Catena, vol. 116, pp. 68-77, 2014.

[11] X. Liu, X. Mei, Y. Li, Q. Wang, Y. Zhang, and J. Porter, "Variation in reference crop evapotranspiration caused by the Angstrom-Prescott coefficient: locally calibrated versus the FAO recommended”, Agric. Water Manage., vol. 96, pp. 1137-1145, 2009.

[12] X. Tang, N. Song, G. Tao, Z. Chen, and J. Wang, "Spatial distribution of main parameters of the Hargreaves formula in typical time scales in Huang-Huai-Hai Plain,” Transactions of the CSAE, vol. 32, pp. 63-70, 2016. 
[13] Y. Liu, and Y. Luo, "A consolidated evaluation of the FAO-56 dual crop coefficient approach using the lysimeter data in the North China Plain,” Agric.Water Manage., vol. 97, pp. 31-40, 2010.

[14] G. Hammer, G. McLean, S. Chapman, B. Zheng A. Doherty, and M. Harrison, et al., "Crop design for specific adaptation in variable dryland production environments," Crop Past. Sci., vol. 65, pp. 614-626, 2014.

[15] S. Wang, W. Zhang, Y. Zhan, and J. Xu, "ET 0 forecasting model in north Henan province based on weather forecast,” J. Irrig. Drain., vol. 30, pp. 84-87, 2011.

[16] S. Wang, A. Duan, and J. Xu, "Dynamic changes and simulation model of plant height and leaf area index of winter wheat,” J. Irrig. Drain., vol. 29, pp. 97-100, 2010.

[17] X. Wen, J. Si, Z. He, J. Wu, H. Shao, and H. Yu, "Support-vectormachine-based models for modeling daily reference evapotranspiration with limited climatic data in extreme arid regions," Water Resour. Manag., vol. 29, pp. 3195-3209, 2015. 